Full length article

\title{
Assessment and locomotion motivational concerns in Internet Addiction Disorder
}

\author{
A. Biraglia ${ }^{\text {a }}$, A. Brizi ${ }^{\text {b }}$, V. Salvati ${ }^{\text {, }}$, R. Metastasio $^{\text {b }}$, L. Mannetti $^{\text {b, * }}$ \\ a Leeds University Business School, The University of Leeds, UK \\ b Sapienza University of Rome, Department of Developmental and Social Psychology, Italy \\ c Sapienza University of Rome, Department of Dynamic Clinical Psychology, Italy
}

\section{A R T I C L E I N F O}

\section{Article history:}

Received 16 January 2017

Received in revised form 14 June 2017

Accepted 3 August 2017

Available online 4 August 2017

\section{Keywords:}

Assessment

Locomotion

Internet Addiction

Gender

Regulatory modes

Self-regulation

\begin{abstract}
A B S T R A C T
Internet Addiction Disorder (IAD) has recently been linked to different personality characteristics and self- orientations. Through a survey comprising 469 respondents, who ranged from 13 to 42 years old, we examine how different regulatory mode orientations (namely assessment and locomotion) relate to the Internet Addiction Test (IAT). Specifically, we find that individuals with a higher level of assessment (the regulatory mode concerned with critical evaluation) also present higher scores in the IAT. This effect seems more pronounced for males than for females. Conversely, higher levels of locomotion (typical of individuals who are oriented to get things done) are negatively related to IAT scores. These results offer important insights for advancing the theory on IAD development and regulatory modes. Further studies are needed to clarify the causal direction of the relationship and to test possible strategies targeted at reducing IAD by modifying levels of locomotion and assessment orientations.
\end{abstract}

๑) 2017 Elsevier Ltd. All rights reserved.

\section{Introduction}

As the availability of faster internet connections has spread throughout the world, the time individuals spend online has increased drastically. It has been estimated that people have doubled the average time they spend online in a week compared to a decade ago (Ofcom, 2015). For individuals less than 16 years old, Internet use has even overtaken the use of television, becoming the occupation where most time is now spent (Childwise, 2016).

The excessive use of the internet by individuals (for work and leisure), defined as, "an individual's inability to control his or her Internet use" (Park et al., 2013, p. 7), that can lead to psychological dependence and damage in the individuals, has been extensively investigated in recent years, in order to identify possible antecedents.

The study presented here aims to assess if individual differences at the level of self-regulatory motivational dimensions could provide further insights into explaining the tendency towards greater Internet usage. We look at a specific model, advanced by Kruglanski et al. (2000), which distinguishes two functional dimensions of

\footnotetext{
* Corresponding author. via dei Marsi 78, 00185, Rome, Italy.

E-mail address: lucia.mannetti@uniroma1.it (L. Mannetti).
}

self-regulation, namely locomotion and assessment concerns. We test our predictions in a sample of individuals of different ages, who had not been previously diagnosed with Internet addiction disorder (IAD). In the following sections, after summarizing the literature concerning IAD and Regulatory Mode Theory (RMT), we present our study, discussing how its results contribute to the literature on both Internet addiction and regulatory motivational orientations, and, finally, we suggest future research directions, as well as potential implications for practice.

\subsection{Previous studies of Internet Addiction Disorder}

Goldberg (1995) first coined the term Internet Addiction Disorder (IAD), and Young (1998) then described this pathological obsession as a compromising condition of self-control.

Diagnostic indicators of IAD include, as for other forms of dependence, over-use, abstinence, addiction, and negative effects on individuals' health and social interactions. In particular, abstinence leads to anger, frustration, and depression, while addiction engenders the desire for longer exposure to the Internet, together with more and more advanced hardware and software. Young $(1998,1999)$ also created a diagnostic instrument, the Internet Addiction Test (IAT) that in its second 20 items version (IAT2) has 
been translated and validated in Italian (Ferraro, Caci, D'Amico, \& Di Blasi, 2007). The Italian questionnaire covers the six crucial aspects of IAD: (1) compromised social quality of life; (2) compromised individual quality of life; (3) compensatory usage of the Internet; (4) compromised academic/working careers; (5) compromised time control; and (6) excitatory usage of the Internet.

After Young's conceptualization, an increasing number of scholars have focused their attention on finding potential antecedents of IAD as well as on developing psychometric instruments to diagnose IAD (Anderson, 2001; Chen, Weng, Su, Wu, \& Yang, 2003; Ko, Yen, Chen, Chen, \& Yen, 2005, 2012; Shapira et al., 2003). In a recent meta-analysis, Kuss, D Griffiths, Karila, and Billieux (2014) show that 68 studies on IAD have been published since 2000.

The literature in the last 20 years has often related excessive internet use to different potential antecedents such as: sociocultural and familial risk factors, neurological malfunctioning personality disorders, mood disorders, and obsessive compulsive disorders (OCD).

As far as familiar factors are concerned, there are studies (Ary et al., 1999; Ko et al., 2005)) that pointed out a strong correlation between repeated conflict within the household, lack of parental control, and the development of IAD in children and adolescents.

Concerning biological antecedents, Malygin, Khomeriki, Smirnova, and Antonenko (2013) showed how adolescents affected by an internet addiction also presented malfunctioning activities of the frontal lobes, resulting in slower mental processes, reduced dynamism of cognitive capabilities, impulsiveness, and even echopraxia.

Previous research has extensively investigated the role personality characteristics may play in leading individuals (especially younger ones) to develop an Internet addiction. These include elements such as difficulties in communicating directly, a sense of loneliness, and a refusal to face up to problems and responsibilities (Chudova, 2002). Hence, individuals may compensate for deficiencies in their direct social interactions through the abnormal use of services, such as chat rooms, blogs, or interactive game platforms (Malygin, Khomeriki, \& Smirnova, 2009; Whang, Lee, \& Chang, 2003). In their analysis, Floros and Siomos (2014) examined 34 studies that relate a personality characteristics model to IAD. The results highlighted a positive correlation between IAD and traits such as psychoticism, sensation-seeking, and neuroticism. On the other hand, IAD was found to be negatively correlated with extraversion, conscientiousness, reward dependence, agreeableness, and self-directness.

Specifically, this last factor demonstrated high consistency across different cultures (Sariyska et al., 2014). Concerning mood disorders, Ha et al. (2007) suggested that reduced ability to control internet use is more frequent at a younger age, while pathological internet use is significantly related to low self-esteem and depressive patterns (Jang, Hwang, \& Choi, 2008; Ko et al., 2012; Ko et al., 2005; Yen, Ko, Yen, Wu, \& Yang, 2007).

Furthermore, Shapira, Goldsmith, Keck, Khosla, and McElroy (2000) pointed out how OCD can be correlated with excessive Internet use, showing that $15 \%$ of subjects who were classified as Internet addicts also presented OCD symptoms.

The present study adds to previous literature by suggesting that IAD might be differentially related to two different motivational concerns (often labeled regulatory modes), namely locomotion and assessment motivational concerns. In the following, we shall briefly illustrate Regulatory Mode Theory (Higgins, Kruglanski, \& Pierro, 2003; Kruglanski et al., 2000), and explain why we hypothesize that the two motivational concerns, as defined by this theory, might provide a useful new perspective to better understand IAD.

\subsection{Regulatory Mode Theory and research}

Regulatory mode theory distinguishes two motivational orientations: locomotion and assessment (Higgins et al., 2003; Kruglanski et al., 2000). Assessment is defined as, "the comparative aspect of self-regulation concerned with critically evaluating entities or states, such as goals and means, in relation to alternatives in order to judge relative quality" (Kruglanski et al., 2000, p. 794). Critical evaluations include questions such as: "What are my options?" "Are there any other possibilities worth considering?" and "Which alternative is best?" Individuals with strong assessment indicators are preoccupied with these kinds of critical evaluations (see Higgins et al., 2003). In contrast, locomotion is defined as, "the aspect of self-regulation concerned with movement from state to state and with committing the psychological resources that will initiate and maintain goal-related movement in a straightforward and direct manner" (Kruglanski et al., 2000, p. 794). In the locomotion mode, individuals emphasize "doing", "getting on with it", and "making something happen" (Higgins et al., 2003). There is substantial evidence that stronger locomotion concern (Chernikova et al., 2016; Higgins, Pierro, \& Kruglanski, 2007; Kruglanski et al., 2000; Pierro, Kruglanski, \& Higgins, 2006) is related to various measures of task orientation, achievement orientation, intrinsic motivation, self-esteem, and the Big Five personality traits (Costa \& McCrae, 1992) of extraversion and conscientiousness. On the other hand, the assessment orientation is positively related to fear of invalidity, discomfort with ambiguity, need for social comparison, and fear of failure. As they have a pervasive concern with appraisal and evaluation, individuals high in assessment concerns are more extrinsically motivated toward tasks (Kruglanski et al., 2000; Pierro et al., 2006), and more prone to counterfactual thinking and regret (Pierro et al., 2008).

The motivational concerns variables are independent of one another, so that a person can have one mode dominate the other, can have strong tendencies in both orientations, or can have weak tendencies in both orientations. Furthermore, locomotion and assessment orientations beyond being chronic individual features (Higgins et al., 2003), can be also increased or decreased by situational factors as has been shown in several experimental studies (e.g., Avnet \& Higgins, 2003; Benjamin \& Flynn, 2006; Cesario, Higgins, \& Scholer, 2008; Mannetti et al., 2009; Pierro et al., 2008). Such procedures range from a direct verbal instruction to think of previous experience of locomotion or assessment states (Avnet \& Higgins, 2003) to movement or assessment focused deliberation instructions (Scholer \& Higgins, 2011).

A comprehensive series of studies, in which the two regulatory orientations have been both measured and experimentally induced, have shown that locomotion and assessment orientation relate to distinct task orientations and motivational emphases (Higgins et al., 2003; Kruglanski et al., 2000). There is substantial evidence (Higgins et al., 2003; Kruglanski et al., 2000) that stronger locomotion is associated with a commitment to prompt action, the ability to stay focused on a task, and conscientiousness. In contrast, assessment is strongly associated with fear of invalidity, selfconsciousness, a need for social comparison, and instability in evaluations over time (both for self as target and for other targets of evaluation). On the whole, this pattern of relations strongly supports the regulatory mode's conceptualization of persons high in locomotion as individuals who quickly initiate action and then maintain it without disruption, and of persons high in assessment as individuals focused on the evaluative aspects of self-regulation in relation to standards and reference points that can change over time. In order to understand how these two regulatory orientations may be related to the tendency toward Internet usage, we focused on the two main affordances provided by Internet: the easy access 
to a huge amount of all types of information, and the opportunity for a computer mediated interpersonal interaction.

From previous literature on locomotion and assessment motivational concerns, we can derive the prediction that easy access to large amounts of information will be appealing for individuals with high levels of assessment, but not for individuals with high levels of locomotion. In fact, on the Internet, one can find several opportunities to compare and evaluate offers, to compare one's own performance with that of others, and so on. These are all tasks of very little appeal to individuals with a predominantly locomotion orientation.

To understand the opportunities provided by computer mediated interpersonal interactions, it may be useful to compare some of their features to contemporary, everyday, face-to-face interactions. Face-to-face interactions are often hectic and require immediate action and choice, and involve different communicative channels (verbal, non-verbal).

Individuals are constantly exposed to social evaluation by others without having the possibility to consider carefully what is the best way to say something. On the contrary, on-line social interactions afford individuals the possibility of taking time before any interaction, looking for more information on others with whom they may (or may not) decide to interact, carefully choosing both the targets and the contents of messages. Given the above differences between face-to-face and on-line social interactions and the specific interests associated with high locomotion and high assessment orientations, we anticipate that online social interaction afforded by Internet use will appeal much more to people characterized by high levels of assessment than to people characterized by high levels of locomotion.

On the whole, considering both the main affordances provided by Internet use, access to information and to mediated interpersonal relations, we hypothesized that locomotion and assessment orientations would have independent and opposite impacts on the tendency towards Internet usage. In particular, we hypothesized that assessment orientation would be positively related to Internet usage, and that the locomotion orientation would be negatively related to Internet usage. Both of these predictions have never been articulated or tested before.

\section{Methods and procedures}

\subsection{Data collection and participant profile}

Respondents ( $\mathrm{N}=469$ ) were asked to complete our survey in one of the largest cities in Italy. We implemented the data collection in two different contexts. The first set of participants was drawn from a secondary school $(\mathrm{N}=280)$, while the second set was drawn from first year undergraduate students $(\mathrm{N}=189)$. Respondents from the secondary school ranged in age from 13 to 20 years old ( $M=16.17, S D=1.42)$ and were mostly female $(66.9 \%)$. For respondents under the age of 18 , an informed consent form was acquired from a parent (Tinson, 2009).

University students were invited to fill in an on-line questionnaire at the beginning of the classes in Social Psychology and received a credit in exchange. The ages of the second set of participants ranged from 20 to 42 years $(M=20.1, S D=1.42)$ with a higher proportion of females (65.1\%). As we used the same measures in both questionnaires and no specific differences were identified across the subsamples, we merged the datasets in a single Statistical Package for Social Sciences (SPSS) matrix, with a total of 469 usable participants. The age of the respondents varies from a minimum of 13 years old to a maximum of 42 years old $(\mathrm{M}=17.7, \mathrm{SD}=2.69)$. Concerning respondents' gender, the sample had a majority of female respondents $(\mathrm{N}=331,66.3 \%)$.

\subsection{Measures}

\subsubsection{Assessment and locomotion}

We measured assessment and locomotion using the scale developed by Kruglanski et al. (2000). The measure comprises two independent 12-item subscales, one for assessment and one for locomotion. Participants were requested to indicate their degree of agreement or disagreement with each of the items on a 7-point scale. Example items included: "I spend a great deal of time taking inventory of my positive and negative characteristics" and "I often compare myself with other people" for the assessment subscale, and "When I decide to do something, I can't wait to get started" and "I don't mind doing things even if they involve extra effort" for the locomotion subscale. Cronbach's Alpha for the assessment subscale is 0.73 , and for the locomotion subscale is 0.77 .

\subsection{Internet addiction disorder}

We used the Italian version, the 20 -item scale of the IAT (Ferraro et al., 2007).

Example items of this measure were "How often do you find that you stay online longer than you intended?', “How often do you lose sleep due to late-night log-ins?" and "How often do you choose to spend more time online over going out with others?" Participants were requested to answer on a 5 point scale. Cronbach's Alpha for this scale is 0.86 . A general IAT score was then created for each subject summing up the different items. The minimum score is 20 , and the maximum is 100; the higher the score, the greater the problems Internet use causes. Young (1999) suggests that a score of 20-39 points indicates an average on-line user who has complete control over his/her usage; a score of 40-69 signifies frequent problems due to Internet usage; and a score of 70-100 means that the Internet is causing significant problems.

The distribution of IAT scores in the present study ranges from 20 to 77 , with $62.7 \%$ of participants with scores between 20 and 39, corresponding to an average user with complete control over his/ her usage, $37.1 \%$ of participants with scores between 40 and 69 , which indicates frequent problems due to Internet usage, and only $0.2 \%$ of participants with score between 70 and 77 , which indicates that Internet usage is causing significant problems.

\section{Results}

We first standardized the three main constructs to control for the different scale anchoring. The variables all presented good internal reliabilities and low correlations (Table 1), with the highest correlations being between assessment and IAT score $(r=0.359)$ and between locomotion and the IAT score $(\mathrm{r}=-0.275)$. Furthermore, gender (coded as females $=+1$, and males $=-1$ ) presented a positive high correlation with locomotion $(r=0.203)$, suggesting female respondents report higher scores on the locomotion subscales. Similarly, age positively correlated with the level of assessment $(r=0.127)$, suggesting older respondents score higher on this variable.

We then tested the main effect of the two predictors, locomotion and assessment, on the IAT as well as the possible interactions between the predictors and respondents' age and gender. We then ran a multiple regression analysis with the IAT score as the dependent variable and locomotion, assessment, age, gender, and the locomotion by assessment interaction plus the interactions of each regulatory orientation with age and gender. Results of this

\footnotetext{
${ }^{1}$ Full information on descriptive statistics and distributions of variables used in the study is available in Appendix 1.
} 
Table 1

Cronbach's $\alpha$, Means, Standard Deviations, and Correlations involving all variables from the study (N 469).

\begin{tabular}{|c|c|c|c|c|c|c|c|c|c|}
\hline & & $\alpha$ & M & SD & 1 & 2 & 3 & 4 & 5 \\
\hline 1 & Assessment & 0.73 & 3.40 & 0.83 & - & & & & \\
\hline 2 & Locomotion & 0.77 & 4.28 & 0.73 & -0.003 & - & & & \\
\hline 3 & IAT & 0.86 & 37.55 & 9.63 & $0.359^{* *}$ & $-0.275^{* * *}$ & - & & \\
\hline 4 & Gender $^{\mathrm{a}}$ & - & - & - & $0.095^{*}$ & $0.203^{* * *}$ & $0.103^{*}$ & - & \\
\hline 5 & Age & - & 17.71 & 2.69 & $0.127^{* *}$ & -0.070 & 0.079 & $0.095^{*}$ & - \\
\hline
\end{tabular}

Notes:

${ }^{*} p<0.05 ;{ }^{* *} p<0.01 ;{ }^{* * *} p<0.001$

a Females $=1$; Males $=-1$.

analysis show that the relationship of the predictors to the IAT score is globally significant $\left(F_{(11,457)}=13.397 ; p<0.001\right)$. Looking in detail at the impact of individual predictors (Table 2), we can see that, as hypothesized, the assessment orientation has a strong positive association $(\beta=0.385, p<0.001)$, and the locomotion orientation has a strong negative association $(\beta=-0.272$, $p<0.001$ ) with the IAT score. The interaction between the two regulatory modes is not significant, confirming the independent effect of the two orientations. Further significant effects are the assessment by gender $(\beta=-0.100, p<0.05)$, and the assessment by age $(\beta=0.09, p<0.05)$ interactions.

We then performed a single slope analysis (Aiken, West, \& Reno, 1991) to explore the two significant interactions. As far as the assessment by gender interaction is concerned, simple slope analysis revealed that among the female participants, the relationship between assessment and IAT scores was not significant $(\beta=-0.24$, $\mathrm{t}=-1.12, p=0.26)$, whereas among male participants it was significant $(\beta=0.27, \mathrm{t}=5.15, p<0.001)$. Fig. 1 , following the procedure suggested by Aiken et al. (1991), reports the estimated means for IAT scores computed for male and female participants at $1 \mathrm{SD}$ below, at the mean and at 1 SD above the mean of Assessment.

As far as the assessment by age interaction is concerned, these additional analyses revealed that the relationship between assessment and IAD score was significant, both among younger participants $(\leq 1$ SD below the age mean; $\beta=0.31, t=6.65$, $p<0.001$ ), and among older participants ( $\geq 1$ SD above the age mean, $\beta=0.39, \mathrm{t}=8.76, p<0.001$ ). On Fig. 2, following the procedure suggested by Aiken et al. (1991), we report the means of IAT score estimated for participants with age and assessment at $1 \mathrm{SD}$ below, at the mean, and at 1 SD above, respectively. Looking at Fig. 2 , and taking into account the " $\beta$ " coefficients, we can see that the relationship between IAT and assessment scores is stronger for participants 1SD above mean age.

Table 2

Impact of individual predictors: standardized $\beta$ coefficients, $t$ values, and their statistical significance.

\begin{tabular}{llll}
\hline & $\beta$ Value & $t$ Value & $p$ value \\
\hline (Constant) & & 86.53 & $0.000^{* * *}$ \\
Assessment & 0.385 & 8.73 & $0.000^{* * *}$ \\
Locomotion & -0.272 & -6.10 & $0.000^{* * *}$ \\
Assessment $\times$ Locomotion & -0.059 & -1.39 & 0.165 \\
Gender & -0.029 & -0.680 & 0.495 \\
Age & -0.048 & -1.06 & 0.290 \\
Locomotion $\times$ Gender & 0.021 & 0.48 & 0.635 \\
Assessment $\times$ Gender & -0.100 & -2.24 & $0.025^{*}$ \\
Locomotion $\times$ Age & 0.045 & 1.04 & 0.297 \\
Assessment $\times$ Age & 0.099 & 2.34 & $0.020^{*}$ \\
Locomotion $\times$ Gender $\times$ Age & -0.046 & -1.07 & 0.287 \\
Assessment $\times$ Gender $\times$ Age & -0.081 & -1.82 & 0.069 \\
\hline
\end{tabular}

${ }^{*} p<0.05 ;{ }^{* *} p<0.01 ;{ }^{* * *} p<0.001$.

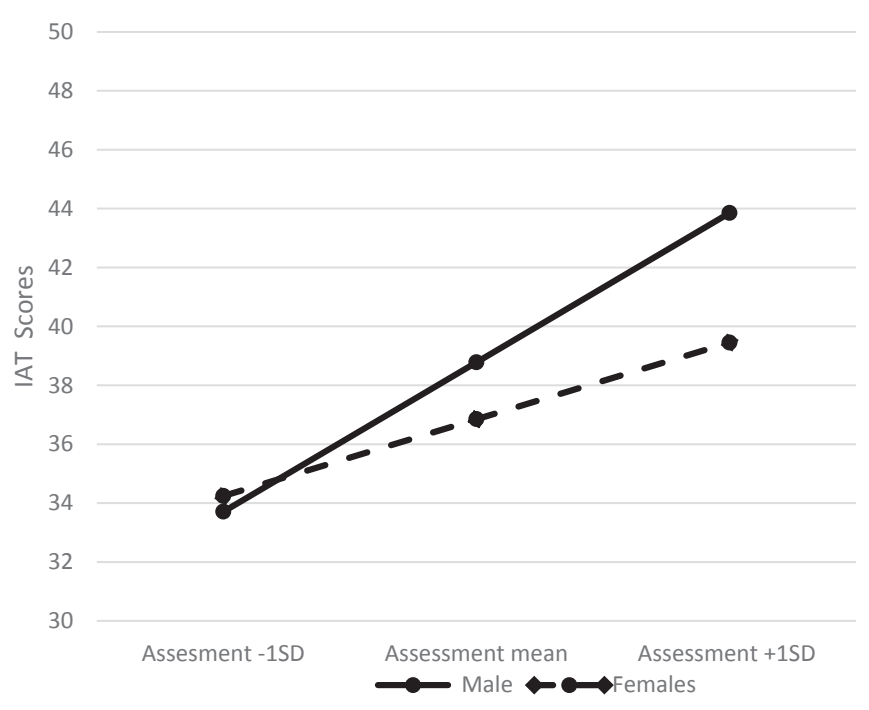

Fig. 1. Means of IAT scores for male and female participants at 1 SD below, at the mean and at 1 SD above the mean of Assessment.

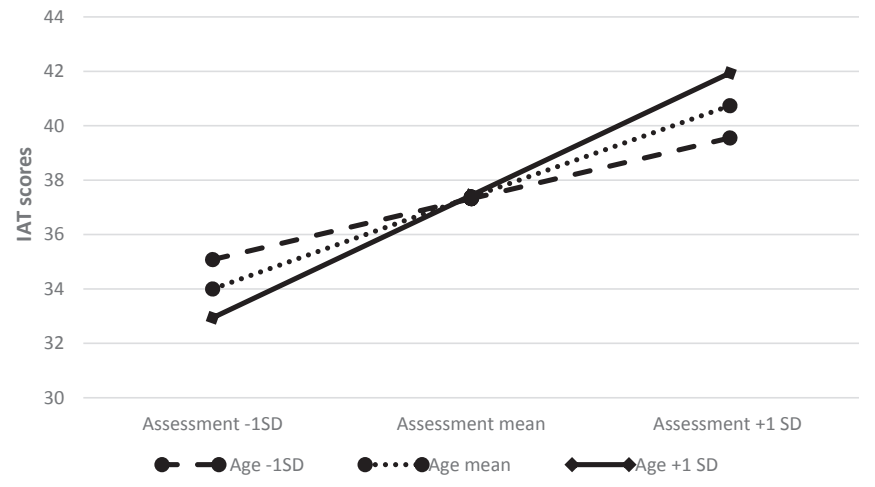

Fig. 2. Means of IAT scores estimated for Age and Assessment: at 1 SD below, at the mean, and at 1 SD above respectively.

\section{Discussion and conclusions}

Results of the present study contribute to the literature concerning excessive use of the Internet by showing that locomotion and assessment regulatory concerns, measured here as stable individual differences, have distinct and opposite relations with the IAT score, used as a measure of Internet Addiction Disorder. As hypothesized, locomotion orientation results are shown to be associated with low levels of reported internet addiction, while assessment orientation is related to higher levels. However, the relationship of assessment orientation with IAT is moderated by age 
and gender: it appears to be less strong among females and very young participants.

Since locomotion and assessment orientations can be modified by situational factors, as extensively shown in previous studies (e.g., Avnet \& Higgins, 2003; Benjamin \& Flynn, 2006; Cesario et al., 2008; Mannetti et al., 2009; Pierro et al., 2008), these results suggest possible strategies to combat increasing Internet usage among the younger population. Capitalizing on the previous literature concerning regulatory orientations, it seems possible to create situations that induce stronger locomotion concerns and lower assessment concerns, using as a starting point procedures applied in experimental studies to prime either a locomotion or an assessment mindset. Furthermore, in everyday persuasion contexts, other, more subtle, priming strategies might be useful. Different types of music (e.g., rock vs. classic), as well as different wall colors (e.g., red vs. blue) or posters showing different scenarios (e.g., urban vs. natural environments) might induce a locomotion or an assessment mindset. These priming strategies should be carefully tested in future research.

However, before exploiting the applied opportunities suggested above, further longitudinal and experimental studies are needed in order to verify that locomotion and assessment motivational concerns have a causal influence on IAD as measured by IAT, since results of the present cross-sectional study do not allow for causal claims. Further causal studies might, in some cases, be implemented in training and educational contexts targeted at young people. In these contexts, different teaching strategies might be designed in order to induce greater orientation to the locomotion concern and lower orientation to the assessment concerns, and then the actual Internet usage of participants might be recorded on a daily basis throughout the training period.

Lastly, in order to prevent an excessive use of indirect forms of social interaction through the Internet, institutions (such as schools and companies) may instead want to provide more opportunities for individuals to express their personality. This solution could be implemented through a series of activities (for example, town hall style meetings or social events) or by designating spaces (common rooms) where individuals can interact instead of spending their spare time on the Internet.

We are aware that the present study has several limits concerning the participants involved, the research design, and the operational definition adopted for the Internet Addiction Disorder. As far as participants are concerned, they were mostly young and did not present specific patterns of IAD; only in a few respondents a high score on the IAT was identified.

Future studies should assess the relation between regulatory modes and IAD in a population with a larger range of IAT scores or that have been diagnosed with this disorder.

Considering the research design, as already mentioned, our cross-sectional study does not allow a causal interpretation of the relations we found. Further experimental studies are needed to test the causal positive impact of the locomotion orientation and the negative impact of the assessment orientation on IAD, as well as longitudinal studies that might help us to understand better how the influence of regulatory orientations on IAD develop with age and whether and how this development is moderated by gender.

Despite these limits, present results contribute substantially to a better comprehension of Internet Addiction Disorder by linking it to two broader motivational orientations that have already been shown to have a causal impact on several behavioral tendencies, ranging from more farsighted economic choices (positively linked to assessment orientation; Mannetti et al., 2009) to more favorable reactions to organizational innovations (Kruglanski, Pierro, Higgins, \& Capozza, 2007). As a whole, we believe this study can constitute an interesting starting point for scholars to further explore the dynamics related to regulatory mode orientations and the diverse use individuals make of internet and social media.

\section{Appendix A. Supplementary data}

Supplementary data related to this article can be found at http:// dx.doi.org/10.1016/j.chb.2017.08.002.

\section{References}

Aiken, L. S., West, S. G., \& Reno, R. R. (1991). Multiple regression: Testing and interpreting interactions. Sage.

Anderson, K. J. (2001). Internet use among college students: An exploratory study. Journal of American College Health, 50(1), 21-26.

Ary, D. V., Duncan, T. E., Biglan, A., Metzler, C. W., Noell, J. W., \& Smolkowski, K. (1999). Development of adolescent problem behavior. Journal of Abnormal Child Psychology, 27(2), 141-150.

Avnet, T., \& Higgins, E. T. (2003). Locomotion, assessment, and regulatory fit: Value transfer from "how" to "what". Journal of Experimental Social Psychology, 39(5), $525-530$.

Benjamin, L., \& Flynn, F. J. (2006). Leadership style and regulatory mode: Value from fit? Organizational Behavior and Human Decision Processes, 100(2), 216-230.

Cesario, J., Higgins, E. T., \& Scholer, A. A. (2008). Regulatory fit and persuasion: Basic principles and remaining questions. Social and Personality Psychology Compass, 2(1), 444-463.

Chen, S. H. W. L., Weng, L., Su, Y., Wu, H., \& Yang, P. (2003). Development of a Chinese Internet addiction scale and its psychometric study. Chinese Journal of Psychology, 45(3), 279-294.

Chernikova, M., Destro, C. L., Mauro, R., Pierro, A., Kruglanski, A. W., \& Higgins, E. T. (2016). Different strokes for different folks: Effects of regulatory mode complementarity and task complexity on performance. Personality and Individual Differences, 89, 134-142.

Childwise. (2016). Childhood 2016. Press Release available online at: http://www. childwise.co.uk/uploads/3/1/6/5/31656353/childwise_press_releasemonitor2016.pdf. (Accessed 10 April 2016).

Chudova, I. V. (2002). Features of the concepts of 'I' and 'internet inhabitant. Psikhologicheski Zhurnal, 22(1), 113-117.

Costa, P. T., \& McCrae, R. R. (1992). Four ways five factors are basic. Personality and Individual Differences, 13(6), 653-665.

Ferraro, G., Caci, B., D'Amico, A., \& Di Blasi, M. (2007). Internet addiction disorder: An Italian study, Cyberpsychology \& Behavior, 10, 170-175.

Floros, G., \& Siomos, K. (2014). Excessive Internet use and personality traits. Current Behavioral Neuroscience Reports, 1(1), 19-26.

Goldberg, I. (1995). Internet addiction disorder- diagnostic criteria. Available at: www.iucf.indiana.edu/ brown/hyplan/addict.html.

Ha, J. H., Kim, S. Y., Bae, S. C., Bae, S., Kim, H., Sim, M., \& Cho, S. C. (2007). Depression and Internet addiction in adolescents. Psychopathology, 40(6), 424-430.

Higgins, E. T., Kruglanski, A. W., \& Pierro, A. (2003). Regulatory mode: Locomotion and assessment as distinct orientations. In M. P. Zanna (Ed.), Advances in experimental social psychology (Vol. 35, pp. 293-344). New York: Academic Press.

Higgins, E. T., Pierro, A., \& Kruglanski, A. W. (2007). Re-thinking culture and personality: How self-regulatory universals create cross-cultural differences. In R. Sorrentino (Ed.), Handbook of motivation and cognition within and across cultures (pp. 102-134). New York: Guilford Press.

Jang, K. S., Hwang, S. Y., \& Choi, J. Y. (2008). Internet addiction and psychiatric symptoms among Korean adolescents. Journal of School Health, 78(3), 165-171.

Ko, C. H., Yen, J. Y. Chen, C. C. Chen, S. H. \& Yen, C. F. (2005). Proposed diagnostic criteria of Internet addiction for adolescents. The Journal of Nervous and Mental Disease, 193(11), 728-733.

Ko, C. H., Yen, J. Y., Yen, C. F., Chen, C. S., \& Chen, C. C. (2012). The association between internet addiction and psychiatric disorder: A review of the literature. European Psychiatry, 27(1), 1-8.

Kruglanski, A. W., Pierro, A., Higgins, E. T., \& Capozza, D. (2007). "On the Move" or "Staying Put": Locomotion, need for closure, and reactions to organizational change. Journal of Applied Social Psychology, 2007, 37(6), 1305-1340.

Kruglanski, A. W., Thompson, E. P., Higgins, E. T., Atash, M. N., Pierro, A., Shah, J. Y., et al. (2000). To "do the right thing" or to "just do It": Locomotion and assessment as distinct self-regulatory imperatives. Journal of Personality- and Social Psychology, 79(5), 793-815.

Kuss, D. J., D Griffiths, M., Karila, L., \& Billieux, J. (2014). Internet addiction: A systematic review of epidemiological research for the last decade. Current Pharmaceutical Design, 20(25), 4026-4052.

Malygin, V. L., Khomeriki, N. S., \& Smirnova, E. A. (2009). Personality characteristics and social risk factors for the formation of the tendency to internet addiction in adolescents. In A. E. Voiskunskii (Ed.), Internet Addiction: Psychological dynamics and developmental tendency (pp. 199-211). Moscow.

Malygin, V. L., Khomeriki, N. S., Smirnova, E. A., \& Antonenko, A. A. (2013). Internet addictive behavior. Neuroscience and Behavioral Physiology, 43(1), 100.

Mannetti, L., Leder, S., Insalata, L., Pierro, A., Higgins, E. T., \& Kruglanski, A. (2009). Priming the ant or the grasshopper in people's mind: How regulatory mode affects inter-temporal choices. European Journal of Social Psychology, 39(6). 
$1120-1125$.

Ofcom. (2015). Adults' media use and attitudes Report 2015. Available online at: http://stakeholders.ofcom.org.uk/market-data-research/other/researchpublications/adults/media-lit- 10years/. (Accessed 10 April 2016).

Park, S. M., Park, Y. A., Lee, H. W., Jung, H. Y., Lee, J. Y., \& Choi, J. S. (2013). The effects of behavioral inhibition/approach system as predictors of Internet addiction in adolescents. Personality and Individual Differences, 54(1), 7-11.

Pierro, A., Kruglanski, A. W., \& Higgins, E. T. (2006). Regulatory mode and the joys of doing: Effects of "Locomotion" and "Assessment" on intrinsic task-motivation. European Journal of Personality, 20, 355-375.

Pierro, A., Leder, S., Mannetti, L., Higgins, E. T., Kruglanski, A. W., \& Aiello, A. (2008). Regulatory mode effects on counterfactual thinking and regret. Journal of Experimental Social Psychology, 44(2), 321-329.

Sariyska, R., Reuter, M., Bey, K., Sha, P., Li, M., Chen, Y. F., \& Feldmann, M. (2014). Selfesteem, personality and internet addiction: A cross-cultural comparison study. Personality and Individual Differences, 61, 28-33.

Scholer, A., \& Higgins, E. T. (2011). Promotion and prevention systems: Regulatory focus dynamics within self-regulatory hierarchies. Handbook of Self-regulation: Research, Theory, and Applications, 143-161.

Shapira, N. A., Goldsmith, T. D., Keck, P. E., Khosla, U. M., \& McElroy, S. L. (2000)
Psychiatric features of individuals with problematic internet use. Journal of Affective Disorders, 57(1), 267-272.

Shapira, N. A., Lessig, M. C., Goldsmith, T. D., Szabo, S. T., Lazoritz, M., Gold, M. S. et al. (2003). Problematic internet use: Proposed classification and diagnostic criteria. Depression and Anxiety, 17(4), 207-216.

Tinson, J. (2009). Conducting research with children and adolescents. Oxford: Goodfellow Publishers.

Whang, L. S., Lee, S., \& Chang, G. (2003). Internet over-users' psychological profiles: A behavior sampling analysis on internet addiction. Cyberpsychology and Behavior, 6(2), 143-150.

Yen, J. Y., Ko, C. H., Yen, C. F., Wu, H. Y., \& Yang, M. J. (2007). The comorbid psychiatric symptoms of internet addiction: Attention deficit and hyperactivity disorder (ADHD), depression, social phobia, and hostility. Journal of Adolescent Health, 41(1), 93-98.

Young, K. S. (1998). Internet addiction: The emergence of a new clinical disorder CyberPsychology \& Behavior, 1(3), 237-244.

Young, K. (1999). Internet addiction: Symptoms, evaluation and treatment. In L. Vande Creek, \& T. Jackson (Eds.), Innovations in clinical practice: A source book (Vol. 17). Sarasota, FL: Professional Resource Press, 19-3. 